\title{
Multiple Wandering Intrauterine Devices and Barriers to Optimal Obstetric Care in Indonesia
}

\author{
Angela Grace ${ }^{1}$, Kevin D Tjandraprawira ${ }^{2}$
}

\begin{abstract}
Aim: To highlight the shortcomings of obstetric care in Indonesia. in low-resource settings. the posterior uterine wall with significant adhesions. An uneventful recovery ensued. and specialist poor settings.

\section{BACKGROUND}

The intrauterine devices (IUD) is an effective and safe contraception. ${ }^{1}$ It is also practical as it may be left inside the uterus for many years before it needs replacing. ${ }^{1}$ However, this practicality has also led to some patients "forgetting" to remove their IUDs. ${ }^{2}$ When IUDs are forgotten, patients may suffer from complications due to the presence of such foreign bodies. ${ }^{3}$ Such cases are preventable but may be inevitable due to a combination of negligence and human errors. Furthermore, management of wandering IUDs is straightforward, as discussed below, but low-resource settings may hamper the recommended management plans.
\end{abstract}

Background:Wandering intrauterine devices (IUDs) is often asymptomatic, but it may also generate significant complaints. While preventable, negligence and human errors could worsen patient outcomes. Management of such cases is usually straightforward but could be hampered

Case description: A 44-year-old para 2 abortus 2 (P2A2) woman with multiple wandering IUDs presented with acute urinary retention and a radiating left lower abdominal pain. A Lippes loop was inserted 19 years ago, which mistakenly was assumed to have been expelled during a miscarriage. A copper IUD was inserted 8 years ago, but she underwent no follow-ups. Abdominal radiograph revealed a copper IUD and another radiopaque foreign body. The copper IUD was successfully removed. Ultrasound revealed no intrauterine Lippes loop. Lack of on-site obstetricians/gynecologists led to her referral. Exploratory laparotomy was performed. The loop was in the rectovaginal pouch embedded to

Conclusion: The lack of on-site specialists and low-resource setting presented unique challenges to this case and underlines the importance of emergency physicians being adept at point-of-care ultrasound (POCUS) in specialist poor low-resource settings.

Clinical significance: Emergency physicians should receive additional training, e.g., ultrasound, to better provide obstetric care in low-resource

Keywords: Contraception, Intrauterine device, Low-resource setting, Missing intrauterine device, Point-of-care ultrasound. Journal of South Asian Federation of Menopause Societies (2019): 10.5005/jp-journals-10032-1179

\section{Case Description}

This is a case of a 44-year-old P2A2 woman in the rural Manggarai regency, East Nusa Tenggara, Indonesia, who unknowingly had been living with two IUDs for 18 years.

The patient presented with acute urinary retention to the accident and emergency department ( $A$ and $E$ ) of a local, lowresource private general hospital in Manggarai regency. She had been experiencing left lower abdominal pain that radiated to her hip and lower back. Neither vaginal discharge nor bleeding outside her menstrual period was reported.

She had a Lippes loop IUD, which was inserted 19 years ago, and miscarriage 14 years ago with the IUD still inside. It was then assumed that her Lippes loop had been expelled simultaneously along with the products of conception, though she vehemently denied witnessing the IUD's expulsion. She had another miscarriage 12 years ago and underwent dilatation and curettage ( $D$ and $C$ ) but no ultrasound follow-up. In 2010, she had a copper T IUD inserted

\footnotetext{
${ }^{1}$ St. Rafael General Hospital, Cancar, Manggarai Regency, East Nusa Tenggara, Indonesia

${ }^{2}$ Elizabeth Garrett Anderson Institute for Women's Health, University College London, London, United Kingdom

Corresponding Author: Kevin D Tjandraprawira, Elizabeth Garrett Anderson Institute for Women's Health, University College London, London, United Kingdom, e-mail: kevin.tjandraprawira.18@ucl.ac.uk

How to cite this article: Grace A, Tjandraprawira KD. Multiple Wandering Intrauterine Devices and Barriers to Optimal Obstetric Care in Indonesia. J South Asian Feder Menopause Soc 2019;7(2):90-93.

Source of support: Nil

Conflict of interest: None
}

by her local midwife. However, she underwent no follow-up up to 8 years thereafter.

Routine urinalysis revealed positive erythrocyte presence and full oxalate stones, hence her acute urinary retention. An abdominal radiograph demonstrated a slightly displaced copper T IUD and a solid, curved radiopaque foreign body measuring approximately 7 $\mathrm{cm}$ above the copper TIUD (Fig. 1). The shape of the foreign body matched that of a Lippes loop.

The IUD was successfully removed at the $A$ and $E$, which was accompanied by a foul-smelling greenish uterine discharge (Fig. 2). However, the Lippes loop could neither be located nor be retrieved. The absence of an on-site obstetrician/gynecologist eventually prompted an abdominal ultrasound by the emergency physician. The only finding was a slightly thickened fundus but no intrauterine Lippes loop (Fig. 3). 


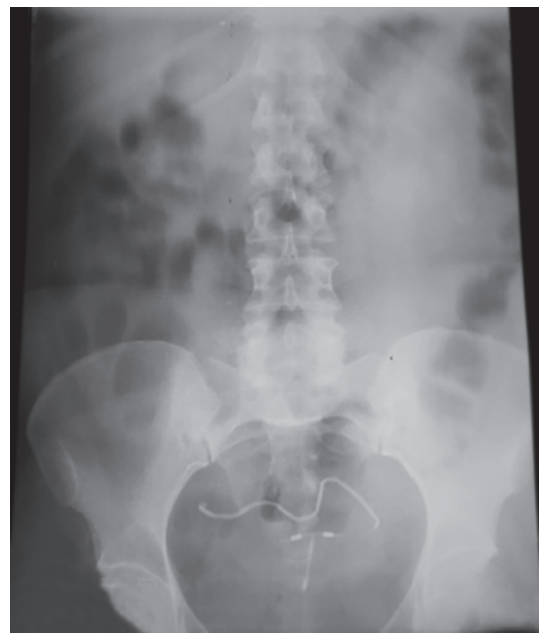

Fig. 1: Abdominal radiograph at presentation

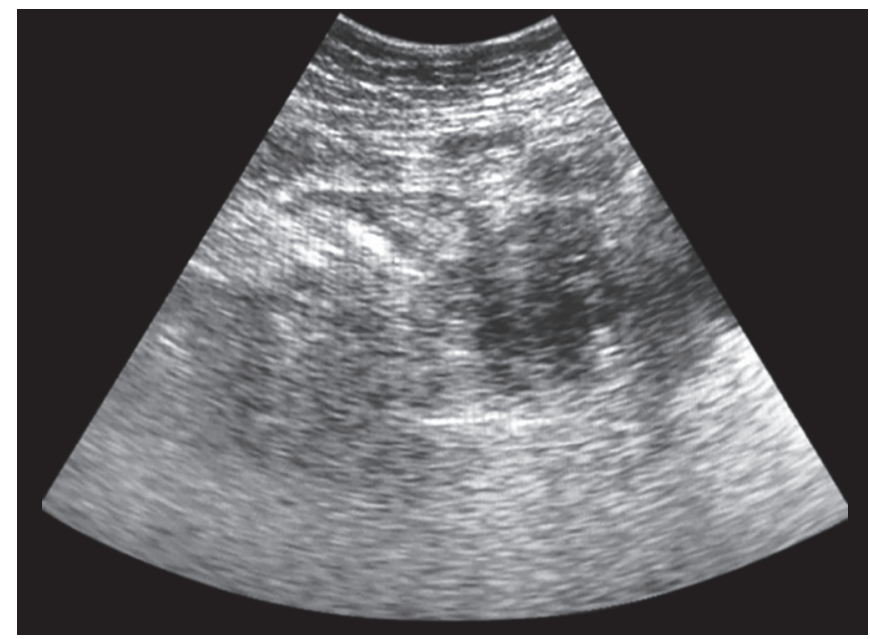

Fig. 3: Experimental abdominal ultrasound to locate the missing Lippes loop

A repeat plain abdominal radiograph revealed the same solid, curved radiopaque foreign body at the exact location seen previously (Fig. 4). This led to suspicion of the loop either being embedded in the uterine fundus or having wandered to the extrauterine cavity.

The patient was admitted overnight, receiving multiple antibiotics (ceftriaxone, doxycycline, and metronidazole) and analgesics. Having counseled the patient on the possible complications of an IUD being left in situ and the available treatment options, she was discharged with a referral to the obstetrician/ gynecologist at the nearest state hospital for further examination and treatment. Upon discharge, her abdominal pain complaints had improved.

Post-discharge follow-up revealed that the patient was scheduled for surgery 3 days later at the regency state hospital. Exploratory laparotomy was successfully performed. During surgery, significant adhesion involving the rectum and posterior wall of the uterus, the left fimbria, and the uterus, along with the right fallopian tube and the peritoneum were discovered. Due to resilient adhesion between the right fallopian tube and the peritoneum, fimbriectomy of the right fallopian tube was not feasible. Left fimbriectomy and adhesiolysis to the rectouterine pouch were then performed.

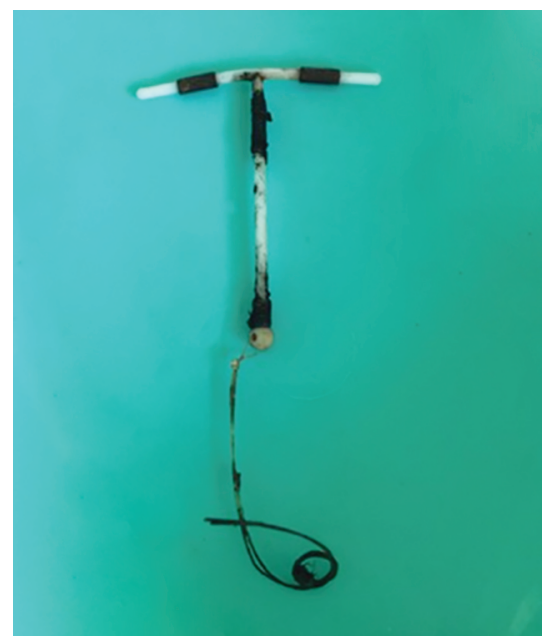

Fig. 2: Copper intrauterine device after extraction

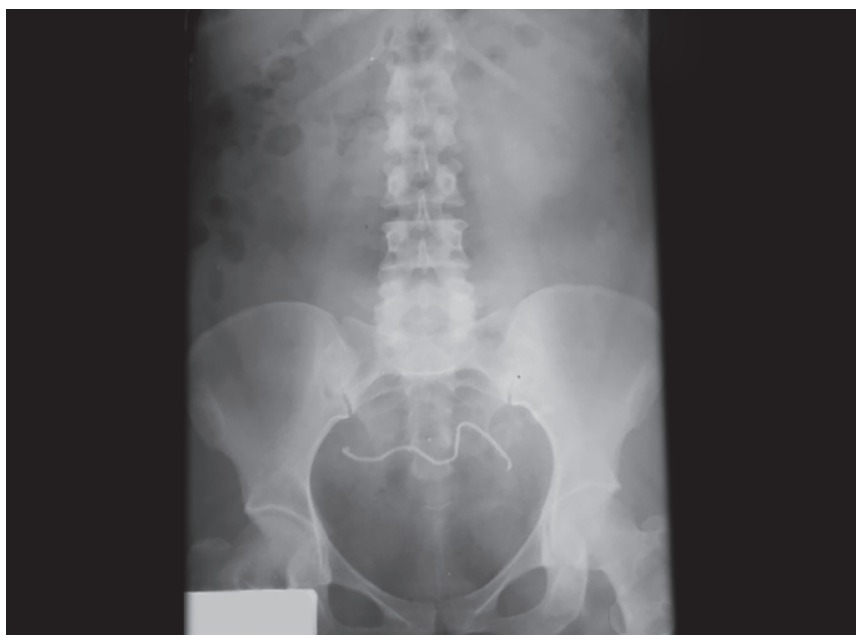

Fig. 4: Abdominal radiograph post copper intrauterine device extraction

The Lippes loop was eventually discovered in the pouch of Douglas embedded to the posterior uterine wall.

Postoperative monitoring entailed no complications. The patient was then discharged, having made an uneventful recovery 2 days after surgery.

\section{Discussion}

The IUD is a contraceptive mainstay. ${ }^{4}$ The first IUD was the Lippes loop, followed by copper-bearing IUDs and currently the levonorgestrel-releasing intrauterine systems (LNGIUSs). ${ }^{4,5}$ Various IUDs prevent pregnancies through different mechanisms. ${ }^{6}$ The Lippes loop induced local endometrial changes by increasing macrophages, fibroblasts, fibrin threads, erythrocytes, and leukocytes. ${ }^{7}$ These cellular changes produce a hostile intrauterine environment impeding sperm passage through the cervical canal and preventing the implantation of fertilized oocytes. ${ }^{8}$ For copper-bearing IUDs, its copper induces an intense local endometrial inflammation and inhibits sperm transport through the cervical mucus and endometrium. ${ }^{6,8}$ With the LNG-IUSs, in addition to the local inflammation, continuous progesterone release leads to endometrial gland atrophy and stromal decidualization. ${ }^{1,6}$ 
Arguably, the most attractive facet of IUDs is the longterm cost-effectiveness. ${ }^{1}$ Inert IUDs (e.g., Lippes loop) could theoretically be left inside the uterus indefinitely. ${ }^{9}$ This corresponds to the case discussed (18 years) and other similar reports (45 and 50 years). ${ }^{10,11}$

However, IUDs also possess several adverse effects. ${ }^{12}$ Early complications include uterine perforation, vaginal bleeding, and lower abdominal pain. ${ }^{12}$ Delayed complications include menometrorrhagia, pelvic inflammatory disease (PID), and "lost" devices. ${ }^{8,12}$ These devices may get "lost" and end up in the extrauterine space. ${ }^{8}$ The most common locations to discover IUDs include the omentum, pouch of Douglas (as is the case discussed), colon, broad ligament, and the mesentery. ${ }^{13}$ Even rarer is finding multiple IUDs in a single female. ${ }^{14,15}$ It is worth emphasizing that these rare cases often present with nonspecific yet confusing symptoms. ${ }^{12}$

The IUDs may go "missing" through various mechanisms. ${ }^{16}$ While uterine perforation at insertion is the most common, IUDs can migrate spontaneously into and through the uterine muscular wall. ${ }^{2}$ Some devices may be embedded deep in the myometrium or gradually perforating to neighboring organs (e.g., bladder and bowels). ${ }^{17-20}$ Missing IUDs may cause significant adhesions, distorting normal pelvic anatomy and causing pain and infertility. ${ }^{21,22}$ This is in line with our case, as she suffered from recurrent miscarriages due to the missing IUD, and intraoperative findings confirming significant adhesions.

For missing IUDs, these devices must be located..$^{23}$ Initial examinations should employ ultrasound, preferably transvaginal, to confirm its intrauterine location. ${ }^{23}$ An abdominal radiograph with multiple views (anterior-posterior and lateral) is required if ultrasound fails to locate the IUD. ${ }^{23} \mathrm{~A}$ computed tomography scan is recommended if abdominal radiograph fails. ${ }^{24}$

The World Health Organization (WHO) strongly recommends the removal of all extrauterine devices, regardless of any symptoms. ${ }^{8}$ This is due to adhesions potentially leading to chronic pain, intestinal obstruction, and infertility as described above. ${ }^{25}$ Another rationale is preventing possible further migration and injury to adjacent structures, which would lead to a more challenging surgery. ${ }^{26}$

The WHO recommendation for laparoscopy as the first-line therapy is widely endorsed. ${ }^{27}$ However, in recent years, this consensus has been challenged. ${ }^{28}$ Markovitch et al. reported successful conservative management of a wandering Lippes loop left for 32 years. ${ }^{29}$ There was also a similar report by Inal et al. ${ }^{30}$ Thus, treatment plans ultimately rests on the patients' autonomy and the resources at the hospital. The latter is particularly represented in this case as the low-resource setting and the lack of on-site obstetrician had made any surgical management unfeasible.

Another issue concerns the negligence and overconfidence of health professionals in the case's history. Regarding IUDs, health professionals are required to perform complete history taking and physical examination prior to IUD placement, proper counseling and detailed explanation on the risks involved, confirmation of the intrauterine placement of the device, and patient follow-up after device placement. ${ }^{31}$ Failures in any of the above may constitute an IUD-related neglect. ${ }^{31}$ In this case, a history of health professionals' carelessness when performing the $\mathrm{D}$ and $\mathrm{C}$ and not confirming proper IUD placement are examples of profound neglect leading to unnecessary harm.
The limited resource setting and unavailability of on-site obstetricians/gynecologists are other examples of shortcomings of the Indonesian healthcare system. The absence of obstetricians led to an ultrasound by emergency medicine (EM) physicians not having adequate ultrasound training. ${ }^{32}$ It underlines the need for proficiency among general physicians to perform point-of-care ultrasound (POCUS) where trained personnel (radiologists and/or obstetrician/gynecologist) are not around..$^{32}$ It has been advocated through devising a customized curriculum that would allow them to perform a plethora of ultrasound examinations, including abdominal and obstetric ultrasonography. ${ }^{33}$

The benefits of POCUS are numerous. ${ }^{34}$ Point-of-care ultrasound allows quick and efficient evaluation of patients with pelvic pain and/or renal colic while "avoiding unnecessary radiation exposure". ${ }^{34}$ Pertinent to our case, POCUS would have enabled the assessment of hydronephrosis and/or bladder distention as our patient presented with acute urinary retention. ${ }^{34}$ The POCUS reduces patients' length of stay in the emergency department without sacrificing quality. ${ }^{35}$ Employing transvaginal ultrasound allows EM physicians to provide more prognostic information to patients presenting with vaginal bleeding. ${ }^{34}$ Finally, POCUS is also utilized in evaluating benign obstetric and gynecologic conditions, such as locating a missing IUD. ${ }^{36}$

However, there are barriers to the acquisition of POCUS competency among EM physicians, and these obstacles are not limited to low- to middle-income countries. ${ }^{32}$ Lack of functional equipment, training, and funding are formidable challenges common to many parts of Indonesia. Still, the advent of innovative programs to encourage POCUS adoption is attractive to address one of the many deficiencies of the Indonesian healthcare system, especially in light of the case currently discussed.

\section{Conclusion}

Wandering IUDs is a common clinical problem with the necessity for proper follow-up. Treatment of asymptomatic cases is controversial; and in low-resource settings, healthcare personnel's negligence, and limited specialists' availability further complicate the management plans. Thus, equipping EM physicians with POCUS skills should be considered to improve obstetric care.

\section{Clinical Significance}

Emergency physicians should receive additional training, such as POCUS skills, to better provide obstetric care, in low-resource settings where there is a possible shortage of on-site specialists.

\section{ACKNowledgment}

The authors express their gratitude to Aurelia Maria Liliweri, MD, for her generous assistance.

\section{References}

1. Stoddard A, McNicholas C, Peipert JF. Efficacy and safety of longacting reversible contraception. Drugs 2011;71(8):969-980. DOI: 10.2165/11591290-000000000-00000.

2. Mitinunwong C, Huang K-G, Thepsuwan J, et al. Forgotten intrauterine device wandering in the abdomen of an endometrial cancer patient. Gynecol Minim Invasive Ther 2014;3:26-27. DOI: 10.1016/j.gmit.2014.01.003. 
3. Turok DK, Gurtcheff SE, Gibson K, et al. Operative management of intrauterine device complications: a case series report. Contraception 2010;82(4):354-357. DOI: 10.1016/j.contraception.2010.04.152.

4. Peipert JF. Lippes loop and the first IUDs: lessons from a bygone era. Am J Obstet Gynecol 2018;219(2):127-128. DOI: 10.1016/ j.ajog.2018.06.001.

5. Lippes J. The making of the first loop. Am J Obstet Gynecol 2018;219(2):203-206. DOI: 10.1016/j.ajog.2018.06.022.

6. Stanford JB, Mikolajczyk RT. Mechanisms of action of intrauterine devices: update and estimation of postfertilization effects. Am J Obstet Gynecol 2002;187(6):1699-1708. DOI: 10.1067/ mob.2002.128091.

7. Sağiroğlu N, Sağiroğlu E. Biologic mode of action of the Lippes loop in intrauterine contraception. Am J Obstet Gynecol 1970;106(4):506-515. DOI: 10.1016/0002-9378(70)90033-5.

8. Group WS. Mechanism of action, safety and efficacy of intrauterine devices. Geneva: World Health Organization; 1987.

9. Thomsen R, Rayl D. Dr Lippes and his loop. Four decades in perspective. J Reprod Med 1999;44(10):833-836.

10. Sinha M, Rani R, Gupta R, et al. Lippes loop inserted 45 years back: the dilemma to remove it or leave it in situ. a case report with review of literature. J Clin Diagn Res 2015;9(4):QE01-QE05. DOI: 10.7860/ JCDR/2015/12981.5832.

11. Aniuliene $R$, Aniulis P. Lippes loop intrauterine device left in the uterus for 50 years: case report. BMC Womens Health 2014;14:97. DOI: 10.1186/1472-6874-14-97.

12. Sun $\mathrm{C}-\mathrm{C}$, Chang $\mathrm{C}-\mathrm{C}, \mathrm{Yu} \mathrm{M}-\mathrm{H}$. Far-migrated intra-abdominal intrauterine device with abdominal pain. Taiwan J Obstet Gynecol 2008;47(2):244-246. DOI: 10.1016/S1028-4559(08)60095-9.

13. Gill RS, Mok D, Hudson M, et al. Laparoscopic removal of an intra-abdominal intrauterine device: case and systematic review. Contraception 2012;85(1):15-18. DOI: 10.1016/ j.contraception.2011.04.015.

14. Tsafrir A, Plotkin V. One intrauterine device lost, two found. Fertil Steril 2008;90(1):185. DOI: 10.1016/j.fertnstert.2007.09.065.

15. Kandirali E, Topcuoglu A, Semerciöz A, et al. Double intrauterine device: presented with protruding urethral stone. Marmara Medical Journal 2008;21(1):61-63.

16. Bharathi RS, Chakladar A, Kumari P. Mystery of the missing loop. Med J Armed Forces India 2011;67(2):177-178. DOI: 10.1016/S03771237(11)60029-4.

17. Kart M, Gülecen T, Üstüner M, et al. Intravesical migration of missed intrauterine device associated with stone formation: a case report and review of the literature. Case Rep Urol 2015;2015:581697. DOI: 10.1155/2015/581697.

18. Takahashi H, Puttler KM, Hong C, et al. Sigmoid Colon Penetration by an intrauterine device: a case report and literature review. Mil Med 2014;179(1):e127-e129. DOI: 10.7205/MILMED-D-13-00268.

19. Subramanian V, Athanasias P, Datta S, et al. Surgical options for the retrieval of a migrated intrauterine contraceptive device. J Surg Case Rep 2013;2013(9):rjt072. DOI: 10.1093/jscr/rjt072.

20. Aydogdu $\mathrm{O}$, Pulat $\mathrm{H}$. Asymptomatic far-migration of an intrauterine device into the abdominal cavity: a rare entity. Can Urol Assoc J 2012;6(3):E134-E136. DOI: 10.5489/cuaj.11100.
21. Knudsen H, Rasmussen K. The "forgotten" intrauterine device: a cause of infertility. Arch Gynecol Obstet 1993;253(3):143-144. DOI: 10.1007/ BF02767331.

22. Haimov-Kochman R, Doviner $\mathrm{V}$, Amsalem $\mathrm{H}$, et al. Intraperitoneal levonorgestrel-releasing intrauterine device following uterine perforation: the role of progestins in adhesion formation. Hum Reprod 2003;18(5):990-993. DOI: 10.1093/humrep/deg203.

23. Penney G, Brechin S, de Souza A, et al. FFPRHC guidance (January 2004). The copper intrauterine device as long-term contraception. J Fam Plann Reprod Health Care 2004;30(1):29. DOI: 10.1783/147118904322701956.

24. Cheung M-L, Rezai S, Jackman JM, et al. Retained intrauterine device (iud): triple case report and review of the literature. Case Rep Obstet Gynecol 2018;2018:8. DOI: 10.1155/2018/9362962.

25. Balci O, Mahmoud AS, Capar M, et al. Diagnosis and management of intra-abdominal, mislocated intrauterine devices. Arch Gynecol Obstet 2010;281(6):1019-1022. DOI: 10.1007/s00404-0101374-8.

26. Balci O, Capar M, Mahmoud AS, et al. Removal of intra-abdominal mislocated intrauterine devices by laparoscopy. J Obstet Gynaecol 2011;31(7):650-652. DOI: 10.3109/01443615.2011.593646.

27. Cetinkaya K, Kumtepe $Y$, Ingec M. Minimally invasive approach to cases of lost intra-uterine device: a 7-year experience. Eur J Obstet Gynecol Reprod Biol 2011;159(1):119-121. DOI: 10.1016/j. ejogrb.2011.07.003.

28. Ertopcu K, Nayki C, Ulug P, et al. Surgical removal of intra-abdominal intrauterine devices at one center in a 20-year period. Int J Gynecol Obstet 2015;128(1):10-13. DOI: 10.1016/j.ijgo.2014.07.025.

29. Markovitch O, Klein Z, Gidoni Y, et al. Extrauterine mislocated IUD: is surgical removal mandatory? Contraception 2002;66(2):105-108. DOI: 10.1016/S0010-7824(02)00327-X.

30. Inal HA, Ozturk Inal Z, Alkan E. Successful conservative management of a dislocated IUD. Case Rep Obstet Gynecol 2015;2015:130528. DOI: 10.1155/2015/130528.

31. Thornton GR. Intrauterine devices: malpractice and product liability. Law Med Health Care 1986;14(1):4-12. DOI: 10.1111/j.1748-720X.1986. tb01665.x.

32. Micks T, Sue K, Rogers P. Barriers to point-of-care ultrasound use in rural emergency departments. CJEM 2016;18(6):475-479. DOI: 10.1017/cem.2016.337.

33. Stolz LA, Muruganandan KM, Bisanzo MC, et al. Point-of-care ultrasound education for non-physician clinicians in a resourcelimited emergency department. Trop Med Int Health 2015;20(8):10671072. DOI: 10.1111/tmi.12511.

34. Whitson MR, Mayo PH. Ultrasonography in the emergency department. Crit Care 2016;20(1):227. DOI: 10.1186/s13054-0161399-x.

35. Stein JC, Wang R, Adler N, et al. Emergency physician ultrasonography for evaluating patients at risk for ectopic pregnancy: a metaanalysis. Ann Emerg Med 2010;56(6):674-683. DOI: 10.1016/j. annemergmed.2010.06.563.

36. Sohoni A, Bosley J, Miss JC. Bedside ultrasonography for obstetric and gynecologic emergencies. Crit Care Clin 2014;30(2):207-226. DOI: $10.1016 /$ j.ccc.2013.10.002. 